\title{
Subacute care funding in the firing line
}

\section{Recent enhancements to subacute care services are threatened due to the uncertain future of federal-state funding agreements}

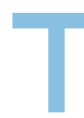

he term "subacute" was coined for use in Australia 21 years ago to describe health care where the patient's need for care is driven predominantly by his or her functional status rather than principal diagnosis. ${ }^{1}$ Subacute care includes rehabilitation, palliative care, geriatric evaluation and management, and psychogeriatrics. Rehabilitation represents more than $50 \%$ of all subacute hospital care in Australia. ${ }^{2}$

The past two decades have seen slow growth in subacute care. However, the public sector was given substantial momentum in recent years through two National Partnership Agreements (NPAs) between the federal government and the state and territory governments, negotiated by the Council of Australian Governments (COAG) - the Hospital and Health Workforce Reform (HHWR) NPA and the Improving Public Hospital Services (IPHS) NPA. Both NPAs aimed to "improve efficiency and capacity in public hospitals". ${ }^{3}$

The 5-year HHWR NPA was signed in 2008 and, of the total funding of $\$ 3042$ million negotiated under this agreement, $\$ 1383$ million was provided by the federal government to the states and territories. This consisted of $\$ 133.41$ million for activity-based funding (ABF) infrastructure, $\$ 500$ million for subacute services, and $\$ 750$ million for "taking the pressure off public hospitals" by addressing waiting lists and times. ${ }^{3}$ The $\$ 500$ million allocated for subacute services was provided in one instalment, with its distribution to all states and territories based on age-weighted population.

The IPHS NPA was signed in 2011. ${ }^{4}$ It consisted of total funding of $\$ 3373$ million, including up to $\$ 1623$ million for new subacute beds. This was allocated over 4 financial years - \$233.6 million in 2010-11, \$317.6 million in 2011-12, \$446.5 million in 2012-13, and \$625.5 million in 2013-14.

Box 1 shows that activity increases in subacute services attributable to the HHWR NPA occurred in all states and territories. More than 600000 extra bed-day equivalents (inpatient days plus ambulatory care equivalents) were provided in 2011-12 than in the baseline year of 2007-08, representing 25.9\% growth across Australia. ${ }^{5}$ The target in the HHWR agreement was a 5\% increase in each of the 4 years - this was exceeded by the end of Year 3 (2011-12).

The 2009 report of the National Health and Hospitals Reform Commission (NHHRC) stated that:

There is ... an urgent need for substantial

investment in, and expansion of, sub-acute services

— the 'missing link' in care — including a major

capital boost to build the facilities required.

It also recommended the introduction of clear targets to increase the provision of subacute services, and stated
Christopher J Poulos MBBS(Hons), PhD, FAFRM Hammond Chair of Positive Ageing and Care ${ }^{\mathrm{T}}$

Kathy Eagar MA, PhD, FAFRM(Hon)
Director $^{2}$

Steven G Faux MBBS, FAFRM(RACP), FFPMANZCA Director of Rehabilitation and Pain Medicine ${ }^{3}$

John J Estel MBBS, MSpMed, FAFRM(RACP)

Director of Rehabilitation ${ }^{4}$

Maria Crotty

BMed, FAFRM, PhD Professor of Rehabilitation and Aged Care ${ }^{5}$

1 School of Public Health and Community Medicine University of New South Wales, Sydney, NSW.

2 Australian Health Services Research Institute, University of Wollongong, Wollongong, NSW.

3 St Vincent's Hospital, Sydney, NSW.

4 St George Hospital, Sydney, NSW.

5 Flinders University, Adelaide, SA c.poulos@unsw.edu.au doi: 10.5694/mjal3.10318 8

\section{destor} details have been released to date.
These two agreements have provided public hospitals with unprecedented opportunities to develop new inpatient and ambulatory rehabilitation services and to expand existing services. These new and expanded services have dealt with previously identified deficiencies, especially the need for early rehabilitation in the acute care setting and increasing the intensity of therapy within rehabilitation settings. ${ }^{8-10}$ Public hospitals have been able to develop better rehabilitation capital infrastructure and better meet the growing need for rehabilitation, particularly among the ageing population. Between them, these two agreements represented a turning point in the development of public sector rehabilitation services across the country.

There is growing international evidence showing improved patient outcomes from the provision of more intense therapy (ie, therapy "dose") in the rehabilitation setting, as well as showing improved efficiency. ${ }^{8,9,11}$ In the United States, where therapy of 3 hours per day for a minimum of 5 days per week is mandated in inpatient Online first 13/05/13

that "Incentive funding under the National Partnership Payments could be used to drive this expansion in subacute services". the targeted $5 \%$ increase per year under the HHWR agreement, recognising that much of this $5 \%$ increase would only account for extra demand associated with population ageing and growth. Indeed, as shown in Box than 5\% growth, with South Australia and Queensland reporting increases of $50 \%$ and $43 \%$, respectively..$^{5}$

The HHWR agreement made provision for a review of progress "in respect of achieving the agreed outcomes", reports of the states and territories describing the services developed under the NPA, and the reporting of of the NPA on a national basis has occurred. Further hough the NPA specifically describes the role of the support for "research into best practice models of care" and funding and providing "national coordination of the initiative [and] monitor[ing] performance", ${ }^{3}$ no provision was made for funding to continue beyond the term of
the NPA, nor for a formal evaluation of outcomes at its conclusion. Consequently, the effectiveness of the they have not been subjected to rigorous evaluation. Although formal outcomes cannot be reported, examples agreement are given in Box 2.

In contrast, the IPHS agreement specifies that an evaluation framework will be developed and that a review of the agreement will be completed, with a decision by COAG by December $2013^{4}$ — although no rehabilitation, ${ }^{9}$ length of stay for patients undergoing 


\begin{tabular}{|c|c|c|c|}
\hline Jurisdiction & $\begin{array}{l}\text { Services in } \\
2007-08 \\
\text { (baseline) }\end{array}$ & $\begin{array}{l}\text { Services in } \\
2011-12\end{array}$ & $\begin{array}{l}\text { Increase (\%) in } \\
2011-12 \text { compared } \\
\text { with baseline }\end{array}$ \\
\hline New South Wales & 679048 & 813283 & $134235(19.8 \%)$ \\
\hline Victoria & 786648 & 933930 & $147282(18.7 \%)$ \\
\hline Queensland & 290368 & 414531 & $124163(42.8 \%)$ \\
\hline South Australia & 197583 & 296604 & 99021 (50.1\%) \\
\hline Western Australia & 511498 & 658781 & $147283(28.8 \%)$ \\
\hline Tasmania & 46815 & 56243 & $9428(20.1 \%)$ \\
\hline Australian Capital Territory & 62745 & 68038 & $5293(8.4 \%)$ \\
\hline Northern Territory & 11227 & 14261 & $3034(27.0 \%)$ \\
\hline All & 2585932 & 3255671 & 669739 (25.9\%) \\
\hline
\end{tabular}

* Compiled from the individual state and territory government reports submitted to the Steering Committee for the Review of Government Service Provision (for Schedule C of the National Partnership Agreement on Hospital and Health Workforce Reform). ${ }^{5}$

stroke rehabilitation is shorter, and the rate of attainment of functional gain is higher, than in Australia. ${ }^{12}$

More intense therapy should result in more efficient use of rehabilitation beds if length of stay can be reduced as a result. This is because the cost of providing extra therapy is relatively low compared with the high fixed costs of running an inpatient bed.

With the HHWR NPA ending on 30 June 2013, many of these new and expanded rehabilitation programs will cease. Staff are already seeking alternative employment, and programs are beginning to wind down. The fact that many health services across the country will now be closing down rehabilitation and other subacute initiatives that were funded under this NPA suggests a lack of planning by the federal, state and territory governments for what would happen after the HHWR NPA ends.

Development of subacute care must continue if Australia is to keep pressure off the acute hospital system and deal effectively with population ageing. However, in our opinion, the lack of requirements for rigorous evaluation of services developed with HHWR NPA funding, which could have provided a basis for ongoing funding if the requirements were met, is not justifiable.

2 Examples of rehabilitation programs funded by the National Partnership Agreement on Hospital and Health Workforce Reform

- At St Vincent's Hospital in Sydney, existing services were enhanced and two new services introduced: rehabilitation in the home, and a mobile rehabilitation team. The latter provides rehabilitation within 3 days of acute admission in parallel with acute care. The program targets young disabled patients for whom there are few community services. Hospital length of stay was reduced and patients avoided inpatient rehabilitation, instead accessing ambulatory programs after discharge.

- In South Australia, large investments were made in home and day rehabilitation services, including substantial investments in Whyalla, Mt Gambier and Berri. The Women's and Children's Hospital in Adelaide is now able to provide multidisciplinary community services, allowing access to community-based rehabilitation for 50 children who have had complex surgery, as well as the establishment of a state-wide hip surveillance program for children with cerebral palsy.

- The South Eastern Sydney Local Health District (SESLHD), one of the largest health districts in New South Wales, focused on increasing intensity of therapy in inpatient rehabilitation and developed acute rehabilitation teams in acute hospitals. The SESLHD has evaluated the outcomes of its enhanced rehabilitation services and reports a 13\% reduction in the average length of stay, improved speed of functional gain, and more than 130 avoided rehabilitation admissions annually.
Even if these programs demonstrate system-wide efficiency gains, this does not free up resources; rather, it increases capacity. As such, it would be difficult for state and territory governments to continue to fund successful programs out of existing resources, unless other programs were cut. The new $\mathrm{ABF}$ arrangements are not sufficient to pick up where the HHWR agreement has left off, not least because federal growth funding does not begin until 2014-15. ${ }^{13}$

At the system level, the sudden closure of rehabilitation and other subacute services will have flowon effects to the acute care system, as it will increasingly have to manage patients who would otherwise have been referred to rehabilitation. The net effect is likely to be that the length of stay in acute care will increase, along with bed occupancy and waiting times.

Competing interests: Christopher Poulos is employed by the University of NSW in a position supported by funding from HammondCare, a not-for-profit provider of a range of health and aged care services, including rehabilitation services. Steven Faux, John Estell and Maria Crotty, while not direct recipients of any funding under these NPAs, are directors of rehabilitation services that have received NPA funding through their respective state government health departments.

Provenance: Not commissioned; externally peer reviewed.

1 Eagar K, Innes K. Creating a common language: the production and use of patient data in Australia. Canberra: Department of Health, Housing and Community Services, 1992

2 Australian Institute of Health and Welfare. Development of nationally consistent subacute and non-acute admitted patient care data definitions and guidelines. Canberra: AlHW, 2013. (AlHW Cat. No. HSE 135.) http://www. aihw.gov.au/WorkArea/DownloadAsset.aspx?id=60129543218 (accessed May 2013).

3 Council of Australian Governments. National Partnership Agreement on Hospital and Health Workforce Reform. COAG, 2008. http://www. federalfinancialrelations.gov.au/content/npa/health_payments/workforcereform/national_partnership.pdf (accessed Apr 2013).

4 Council of Australian Governments. National Health Reform Agreement National Partnership Agreement on Improving Public Hospital Services. 2011. http://www.federalfinancialrelations.gov.au/content/npa/health reform/ national-workforce-reform/national_partnership.pdf (accessed Apr 2013).

5 Steering Committee for the Review of Government Service Provision, Australian Government Productivity Commission. National partnership performance reporting: National Partnership Agreement on Hospital and Health Workforce Reform. http://www.pc.gov.au/gsp/national-partnership/hospital-healthagreement (accessed Apr 2013).

6 National Health and Hospitals Reform Commission. A healthier future for all Australians - final report. Canberra: NHHRC, 2009. http://www.health.gov.au/ internet/nhhrc/publishing.nsf/content/nhhrc-report (accessed Mar 2013).

7 South Eastern Sydney Local Health District. SESLHD COAG subacute programs report: National Partnership Agreement overview 2009/10-2011/12. Sydney: SESLHD, 2012. http://www.seslhd.health.nsw.gov.au/COAG/Report_SESLHD_ OverviewCOAG_SubacuteNationalPartnershipAgreements.pdf (accessed Mar 2013).

8 New PW, Poulos CJ. Functional improvement of the Australian health care system - can rehabilitation assist? Med J Aust 2008; 189: 340-343.

9 Poulos CJ. Evaluating inpatient public rehabilitation in Australia using a utilization review tool developed in North America. J Rehabil Med 2010; 42: 246-253.

10 Poulos CJ, Magee C, Bashford G, Eagar K. Determining level of care appropriateness in the patient journey from acute care to rehabilitation. BMC Health Serv Res 2011; 11: 291.

11 Lee WJ, Cheng YY, Liu CY, et al. Dose-dependent effect of rehabilitation in functional recovery of older patients in the post-acute care unit. Arch Gerontol Geriatr 2012; 54: e290-e293.

12 Teasell R, Meyer MJ, McClure A, et al. Stroke rehabilitation: an international perspective. Top Stroke Rehabil 2009; 16: 44-56.

13 Australian Government. Budget paper no. 3. Part 2: Payments for specific purposes - health. http://www.budget.gov.au/2012-13/content/bp3/html/ bp3_03_part_2b.htm (accessed Apr 2013). 